\title{
我國昆蚌學研究工作現狀的我見
}

\author{
曹磷
}

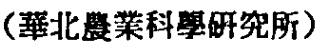

解放五年來，由於堂和政府的重視，治路事

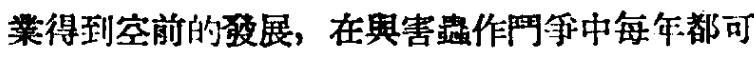
見㺫一些進步。昆息理論研究工作踓然也有進

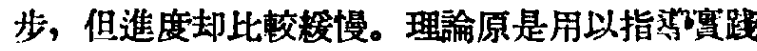

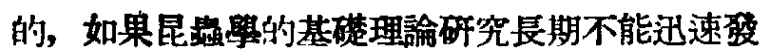

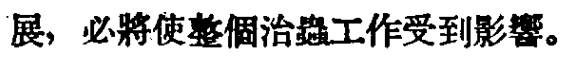

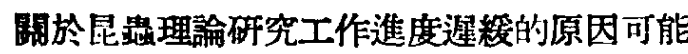
有如下的幾方面:（1）基礎溥弱；（2）試驗研 究工作缺乏梳一領導; (3) 經驗一時遭 不能上 升偽理論。以下想就造三點分别加以討論。

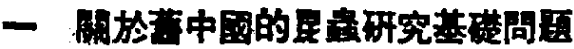

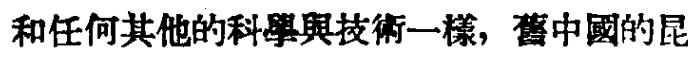

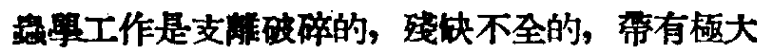
的牛殖民地色彩的, 長久以來就存在着理論興蒠 際脱節的現象. 由於反政政府的極不重視，理論

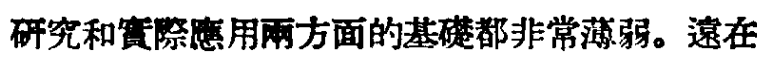
上世紀中菜，各春本主義國家派到中國來的傅敛 士在他們陰險地勘察中國資源之餘, 也從不忘記 搜集中國的動植物標本。昆蜈標本因篇便於探集、 整作、保存和寄送，更是大量被送到國外去定名和 分類。因此，當時開於中國昆越相的基本材料， 可以說全部学握在帝國主毒者的手裏。

到丁本世紀初，以美帝國主義第首的少數所 詡列强，又在中國進行一系列的交化侵略，首先

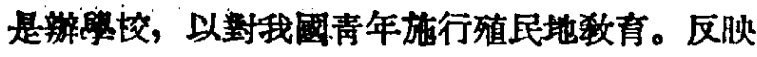

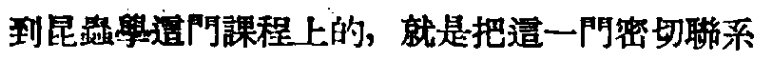

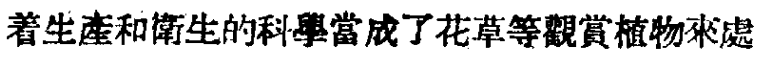
理。在學逐阿課的人，也於不知不學間把研究屁

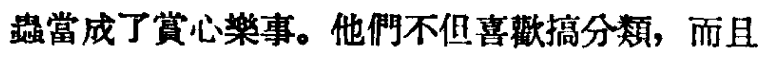
立志要選一个作僻的科、目做研究。很摜坮, 我自

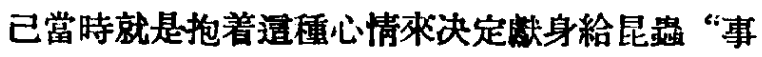

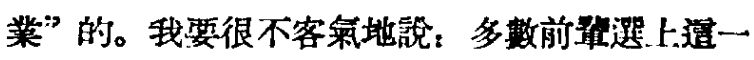
行的時候也是造櫒的心情。我清楚记得有過一個 時期, 大家以舉㕷分類䉆高, 以學替防治第下。 在美國，不是有不少的数授門因第病、害的大

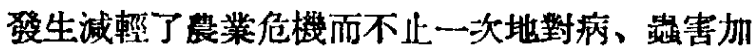
以歌領嗎 ?!

誠然，在解放以前也會有過一支害虫趴方治的 除伍，但說起來筫在太小得可性了。固然不能镜 這段工作完全沟有成績, 只是在缺乏正確思想領 等和工作方法的情况下, 即有一些研究成果也没 有在生產上起到作用。反之，那時在老解放區的 土地上，昆藏學却第一次萌了芽，生了根。那裹 並没有學過昆分分類的，防治的知識也久役得

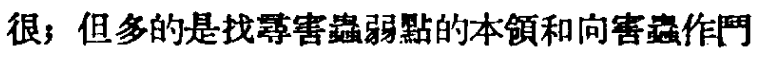
争的决心。那禀根本没有甚悹防治榢, 廣大農民

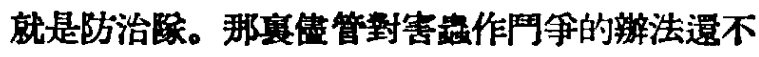

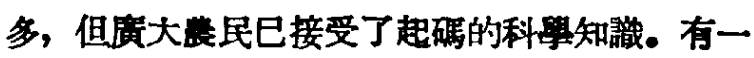

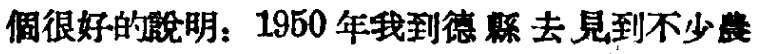

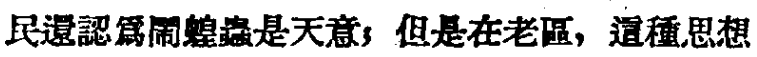
早已被厉篇迷詣、落後了。

總的設來，從辛方革命到全國解放的將近四

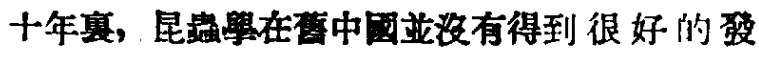
展，更沟有起到虙有的作用。搞分類的人既把自

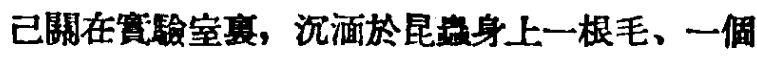
爪的研究，搞防治的人也因篇不受重視和没有䓰 衅基礎, 只能枝枝節節地做工作。只有在解放區,

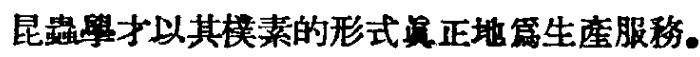

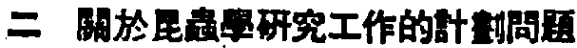

由於黨和政府的重視科研究工作, 近年來 從事昆路研究的人数也在不斷地激势着。拿昆湈 學會會員人數來看, 它已從初解放時的 300 多人 


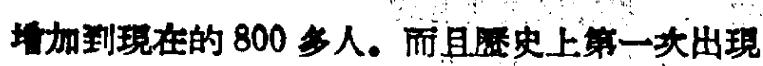

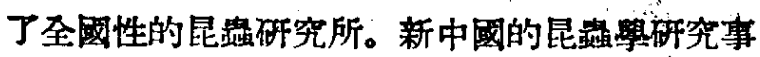
業是具有無限光明前途的。但是因第解放的時間 究竟還短，新生的力量踓然增加得很快，但是研 究昆啮年限較長的人畢竟還少。更重要的是, 雖 然在不斷地進行思想改造, 舊的思想意識仍未能 很块地消除。從興趣出墢的理諭研究固然已在逐 漸縮小其陣地, 是現我們眼前的, 仍有不少不切 合頌際的工作。

因窟一洔找不到更多更好的资料，我曾学试 着分析了“昆暃學報”四年牛來已出版的三突又三 期的文章,墢現在僅有的98篇國人寫作的文章中， 属於形態學和分類學的竟佔 47 篇, 而且其中有些 竟脫離”賢際到使人可憼的地步。自然, 發表在“昆

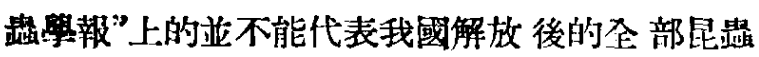
圊研究工作; 但它至少反肤了我國目前還有一部 分有研究能力的昆虫工作者亚沟有把他們的研究 工作和祖國經濟建設的需要密切地結合起來。

作窟一倜科學工作者, 我從不反對理論研究 的重要, 並認識到任何理論研究, 只要方向是正 確的，都可以導致增加人類幸福的結果。但我們 做研究工作應該分别輕重緩急。拿一些現有的形 態和分類研究来看, 如我蝗腹疆器的研究, 我說 不出它對十年以內的國計民生會有那些好處? 把 這類研究推暹到十年以後再去作, 對國計民生又 會有甚公壞處? 分類研究是要的, 因此作学分類 基礎的形態學也有㸴究價做。但目前我國很多 主要害品的分類、分佈還没有得到解决, 而我們 少數同道還在“閉情逸程”地去進行現實意義不大 的䂰究工作，逼就使人難於理解了。

我國正在進行汶會主義建設, 假使我椚在第 一倜五年計劃中不集中主要力量弡展重工業, 而

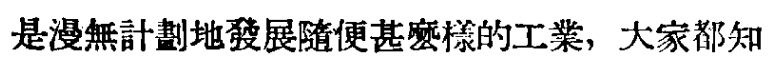
道这是不對的。因此, 我們也没有理由把我們僅 有的一點力量用到也許十年以後戈可能用得着的 研究上去, 而對目前國家的迫切需要熟視無睢。

也許有的同志會說: “堷程研究工作誠 然是 不合特宜的, 但我過去所受的訓練只適合做這栐 的砰究, 多做點總比少 做點好吧?"這種說法也

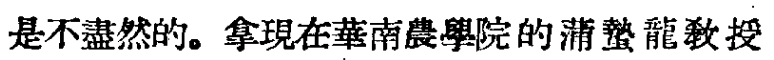
篇例, 他從事牙虾科 (Hydrophilidae) 的分類 研究已有多年歴史, 解放後不久即效然從事彷

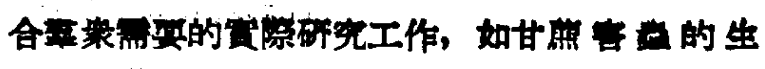
物防治等，而且取得了一定成就。像通類的事

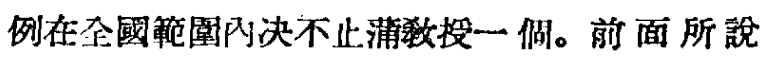
“從與趣出發的理論研究已在逐漸縮小其陣地”,

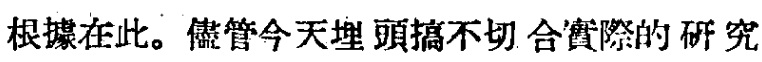
工作的人已是窑察可數, 但這裹所要批制的乃是 盵離資際的思想, 而這種思想在國內 昆路界 還相當普掘; 時常困惑着一些新參加工作的同 志, 因之有必要加以陪清。以分類鼠而言, 它本 身就是一阴科學，有它理論的一面，也有它暂用 的一面。從理論上講, 任何一话程請都有研究的

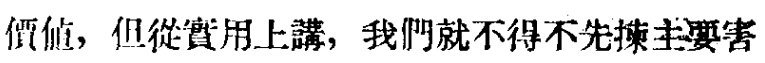
蜫和主要益显聂進行研究, 然後再逐潮撗大, 革命 後的蘇聯走的就是逐雏路子。拿中國現狀來就, 最迫切需要的是結合貨際的基礎理論研究, 像昆

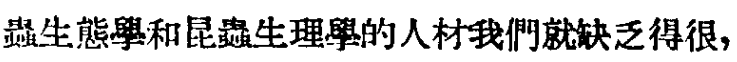

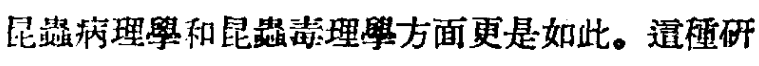
究比分類研究更感到迫切, 且也更輕而易舉, 因 此就更做得我們提倡。不錯, 十八世紀滒洲的昆 濒科學是從形態和分類開始的, 但西㰞各國的工 業是由發展輕工業和交通運輸業開始的，第了大 踏步趕上去, 我們就不能走資本主義國家的路, 只能走䒺聯的路。

最後再略篇說一下應該研究那些阙題与符合 生座上對昆䗉科學的要求。我們今天還没有條件

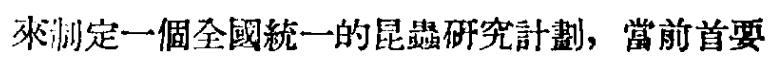
工作是把一切的研究力量集中到生座上來 (包括 減少星傳疾病, 增加生在內)。只要 我們能把 力量轉移到結合䡠際的渞路上來, 任何的研究項 目都必然窖所鹳迎。

\section{三 關於治䖵經驗上升揙理論的問通}

解放以後, 在黨的正確領導下, 工作在農業 研究機關的昆踏工作者, 和其他有關專業一道, 屡開了一次比一次規模大的農村工作。造個運動 的正確性很快地第各方所承認, 影響的面也越來 越廣。於是我們看到了搞街生工作的和敉舆工作 的昆掓工作者, 也在他們業務上歌可的範園內投 入這一運動。到今天没有下過鄉的昆茈工作者可 以說是絕無僅有的了。

這雖然社只是一個開始, 它的影響之大巳經 難於估計的了。最主要的一點: 科學和子民四面 


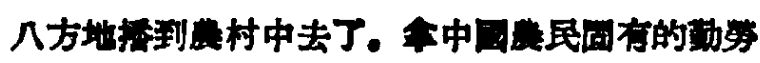

與智意，他們不但很快地接受了新的科悬技街， 而且就便地改進了它。舉例來䛦，科孟工作者提

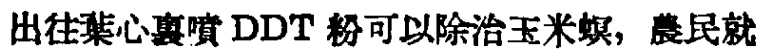

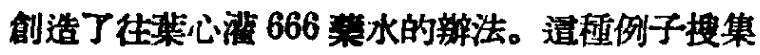
起來是很多的。

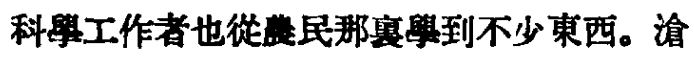
縣茛民創造了用小米飯拌香油放在梨樹上以誘集

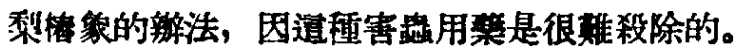
在破生规律上，度民也不比我們知道得少。我們在

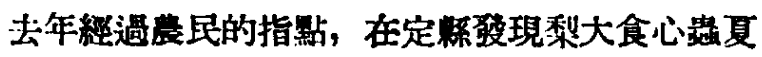

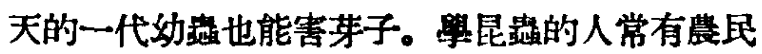

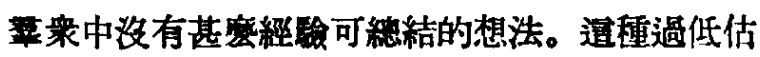
計祖國勞動人民智慧的想法是極端有害的。和中

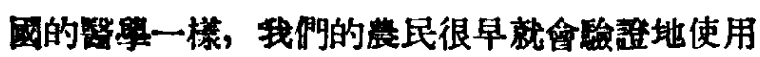

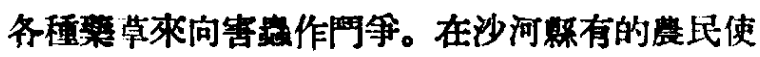

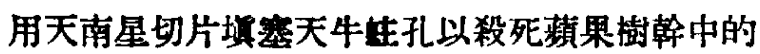

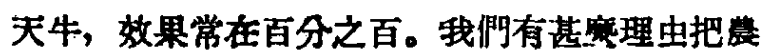
民程验一筆抹殺眤?

不難看出，在解放後的短短五年中，科學在 中国歴史上第一次走上與勞動人民結合的道路。

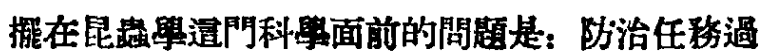
於䇣重，使現有的少數有碎究能力的人員一到售 村去即時投入婜張的戰网中，有时甚至來不及研

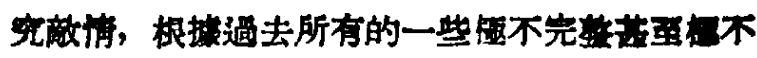
正確的資料，就要定出一套防治辦法。因此在每 年寫總結時, 都不免有很多空白點, 葨至束不及 好好地總結就要開始下一年的工作，使䆓践中得 來的絓驗一特不能上升到理諭的階段。但一切理

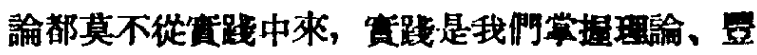
富理論、检验理論唯一的逆路。搞昆工作的人

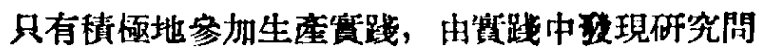
題, 從而做理論方面的提高。

總括全文，我們今天大多數昆工作者，在 黨的領導下，走的路綫是正確的。我們今天的工 作還不能適隹國家和人民的需要，這主要是由於

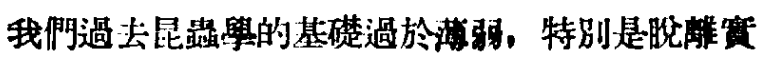
際的工作方法是我們的致命伤。今天我們正在粥

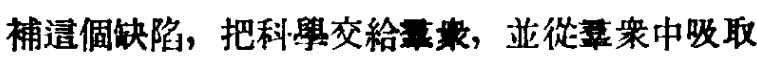

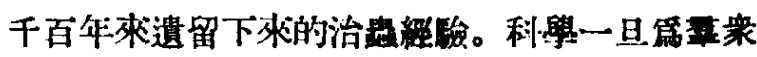
所学握, 就會發出無的力量。遭是解放後塥國 昆踏工作動態的主要方面，也是我們萬不可忽䰝 的一倜方面。

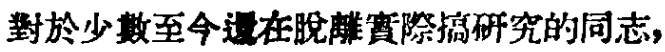

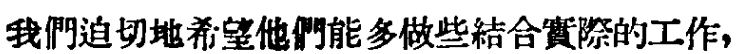
但因篇筆者理睮水平的限制, 䛦服力不强, 甚至 某些笅點可能遑是錯誢的，也一併乔望同道們不 客策地予以批玮、指正。

\section{[上接 55 貝]}

書契在文字舆上的分析有着特别重大的意

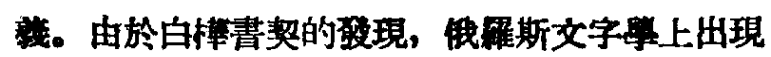
了新的一章一一白模書契的書法。白模書契的青 法有它自己的特點。

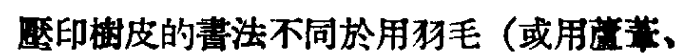
毛筆) 繁水的書法的主要之點在於: 潞印時, 書寫工。具不管在多㦄光滑的書寫材料上也不會随 便滑動。

白棰書契的進一步现, 也就是當墢現那些 有年代的或者没有年代而根樭它上面所提到的歴 史人物（1953 年酸現的一塊 14 世紀後牛柴的書 契上面明白地指出一個諾夫哥羅得城的政治活動 家）能把它歸入某一時期的書契的時候，一定能 更让確地制定白樺書契書法的進化過程。

諾夫哥羅得城白樺書契大大地㖕富了有關古 代俄維斯語言，尤其是諾夫哥羅得城方言所特有
的筑勇现象的現有資料。

白樺書契的造句方面是储得注意的。这些書 笑的全部內容和官方文書的內容大不相同, 它記 的是書信作者親身經歷的而且使他在竄白模畫 契時仍感到非常激勒的事情。白櫵書契是口語的 直接紀錄, 它們幾乎未受文學傅統的影睡; 因 此, 比起其他文铲來, 它们最能无分地表達活的 會話語言所特有的那些句法結構。

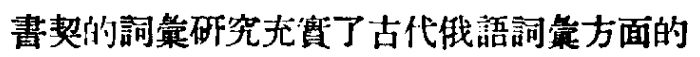
現有资料, 特別是在表達日常生活的概念以及橙 誌相應的物能方面。

由此可見, 諾夫哥羅得城墢現的白樺書契不 僅對俄維斯尼族的歴史來說有 $\mathrm{E}$ 大的科學價值， 因窟它們揭露了交化和生活的很多方面，而且對 俄羅斯語言史隶說也有巨大的科學僄值。

\section{〔本刊特稿劉酒泉钽〕}

